\title{
Editorial on EAIT 2015, Issue 1
}

\author{
Arthur Tatnall
}

Published online: 10 February 2015

(C) Springer Science+Business Media New York 2015

This first issue of Education and Information Technologies for 2015 again illustrates the truly international nature of this journal with articles from the USA, Sweden, the Netherlands, Ireland, India, South Africa, France and Greece. It also illustrates the wide range of topics carried by the journal. In this issue these range from an article on serious game playing in university education to one investigating the attitudes of Greek kindergarten teachers towards computers.

Beginning this new volume of EAIT for 2015 is an article by Christian Sebastian Loh and Yanyan Sheng from Southern Illinois University, USA. Titled: Measuring the (dis-)similarity between expert and novice behaviors as serious games analytics, it examines players' actions and behaviours within an online gaming environment as user-generated data for performance assessment. The research described used string similarity to differentiate likely-experts from a group of unknown performers based on how similar their ingame actions were to those of experts. Their findings indicated that string similarity is viable as an empirical assessment method to differentiate likely-experts from novices and potentially useful as the first performance metric for serious games analytics.

The second article: Finding potential problems in the thesis process in higher education: Analysis of e-mails to develop a support system was contributed by Naghmeh Aghaee from Stockholm University, Sweden. The article begins by noting that some students have difficulty in managing to complete their final year Bachelor's and Master's level project or thesis and goes on to describe an information and communication platform, called SciPro developed in the Department of Computer and Systems Sciences (DSV) at Stockholm University to support students and supervisors during the thesis process. The reported study explored problems learners faced during their final project courses and found six exhaustive and mutually exclusive categories of problems which it categorised as: thesis initiation, info-mail, technical issues, exemption, supervision and final seminar.

Billy R. Brocato from Texas A\&M University, and Alessandro Bonanno and Stacy Ulbig from Sam Houston State University, USA next investigate: Student perceptions and instructional evaluations: A multivariate analysis of online and face-to-face classroom settings. Their reported study examined students' evaluations of faculty

\footnotetext{
A. Tatnall $(\bowtie)$

Victoria University, PO Box 14428, Melbourne 8001, Australia

e-mail: Arthur.Tatnall@vu.edu.au
} 
performance in traditional and online classes. Their study design built on prior research that addressed socially relevant factors such as classroom environments, students' learning goals,expected and received grades, and more importantly students' ratings of instructors' performance. Their results indicate that students' perceptions are different when attending traditional versus online classroom settings, inferring that these require different teaching styles and different evaluation criteria.

On the cybernetic arrangement of feedback in serious games: A systems-theoretical perspective is an article by Wim Westera from the Open University of the Netherlands. The article explores the cybernetic regulation of complex human learning and teaching, and provides a theoretical description of the arrangement of adaptive, machinegenerated learner feedback which relies on cybernetic principles. Although feedback is considered a key element of any learning process, feedback by teachers and educators is difficult because of the ever-growing complexity of learning environments, reinforced by open, online learning technologies and topical models of learning (competence learning, experiential learning,situated cognition, serious gaming). The article explores how cybernetic principles could be implemented in complex learning environments for the arrangement of self-regulating feedback loops for learners.

The next article, by Peter Tiernan from Dublin City University, Ireland is titled: An inquiry into the current and future uses of digital video in University teaching. The author points out that student use of digital video has increased dramatically in recent years, both for personal and academic purposes, and that this suggests opportunities to further incorporate its use in education. After examining current uses of digital video in a wide range of educational settings future opportunities and directions for the use of video in education are discussed, with attention given to the prospect of academic online video platforms. Findings presented indicate that students value the use of digital video in lectures, and would like to see its use become more ubiquitous in education.

A study of usage of symbols and opinionated words in annotation for modeling literature survey experiences is by Archana Shukla and Banshi D. Chaudhary from Motilal Nehru National Institute of Technology, Uttar Pradesh, India. The authors assert that students enrolled in research-based degree programs conduct literature reviews to identify issues to be addressed, but then proceed to annotate these articles either using symbolic markers such as underline, question mark, circle etc. or record their observations, opinion, queries and comments in textual form. These annotations may be recorded either manually using pen or pencil or electronically using any text or word processor tool. The authors have identified eight different types of symbols and a set of words based on a survey of teachers and graduate students, and propose a model using a Resource Description Framework Schema to manage these annotations and literature survey experiences.

In the following article: The role of the strategic and adaptive Chief Information Officer in higher education, Reuben S. Dlamini from the University of the Witwatersrand, Johannesburg, South Africa examines the evolving role of Information Technology executives in higher education, with the objective of detailing skills and experiences necessary to be a Chief Information Officer (CIO), the expectations by the leaders in higher education of these individuals and how leaders in higher education view the role of the CIO. The author explains that the CIO position is no longer mainly focused on technical issues, but has influence on the institution's mission critical strategies. The article discusses three dimensions of the CIO position: skills and experiences,expectations of the leaders in higher education of the CIOs, and how 
leaders in higher education view the role of the CIO. The findings indicated the need for CIOs to have multi-dimensional personalities, diverse work experience and a higher education background with the ability to strategically adapt according to the institution's needs.

Information technologies, students' e-skills and diversity of learning process, by Adel Ben Youssef (University of Nice Sophia Antipolis), Mounir Dahmani (University of Paris-Sud) and Nessrine Omrani (Ecole Polytechnique, Paris, France) describes how universities are making in-depth changes to the nature and form of learning processes, intended to better prepare students for entry into the labour market. In this paper, the authors focus on the evolution of student use of IT in an institution characterised by organisational changes, and analyse the determinants of students' e-skills using a sample set of French university students.

The article that follows: Comparing student and expert-based tagging of recorded lectures analyses the way students tag recorded lectures, and compares their tagging strategy and the tags that they create with tagging done by an expert. The authors: Pierre Gorissen (Fontys University of Applied Sciences), Jan van Bruggen (Open University of the Netherlands) and Wim Jochems (Eindhoven University of Technology) are all from the Netherlands. They investigate the quality of tags students add, and introduce a method of measuring how similar the tags are by the use of vector space modelling and cosine similarity. Their study shows no statistically significant correlation between tag similarity and indicated interest in the course, the perceived importance of the course, the number of lectures attended, the indicated difficulty of the course, the number of recorded lectures viewed, the indicated ease of finding the needed parts of a recorded lecture, or the number of tags used by the student.

William K. McHenry from the University of Akron, USA next contributes an article titled: Selecting teams: The potential of "the Grid". The article investigates the use of a Computer-Based Team Selection Algorithm (CBTSA) in a capstone project course involving Information Systems, Human Resources, and Supply Chain/Operations undergraduate students. In the described research, data from three semesters of the course before this genetic algorithm was put into use are compared to data from three semesters after it was adopted. It was found that students in the CBTSA for med teams experienced considerably less general time, procrastination and motivation problems, or specific scheduling conflicts. The article notes that regardless of improvements to the genetic algorithm used in the CBTSA, it is difficult to provide every team with rich meeting times and still achieve parity for the teams on a number of other criteria.

The final article in this issue: Profiling the attitudes of Greek kindergarten teachers towards computers is by Nicholas Zaranis and Vassilios Oikonomidis from the University of Crete, Greece. The purpose of their reported study was to examine kindergarten teachers' attitudes towards use of computers in the classroom. The research sample consisted of two groups drawn from kindergarten teachers of public kindergartens in the area of Athens and Crete. Cluster analysis was applied to obtain three distinct clusters of the kindergarten teachers' profiles: the neutral, the sceptic and the optimistic kindergarten teachers. These profiles were summarised and the changes of recent years discussed in the hope of providing useful information on the educational challenges of the kindergarten curriculum.

\section{Arthur Tatnall}

Editor-in-Chief 